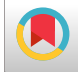

\title{
Exploring Coping Strategies of Healthcare Providers with Tension Sources in Iran-Iraq War: A Qualitative Study
}

\author{
Zahra Farsi ${ }^{1, *}$ \\ ${ }^{1}$ Ph.D., Associate Professor, Faculty of Nursing, AJA University of Medical Sciences, Tehran, Iran
}

"Corresponding author: Zahra Farsi, BScN, MScN, PhD, Associate Professor, Faculty of Nursing, AJA University of Medical Sciences, Kaj St, Shariati St, Tehran, Iran. Tel: +98-2177500404, Fax: +98-2177500929, E-mail: z.farsi@ajaums.ac.ir

Received 2017 August 05; Revised 2017 November 15; Accepted 2017 December 10.

\begin{abstract}
Background: Evidence shows that people, including healthcare providers, use different coping strategies to cope with life changes and the resulting stress. War causes mortality, loss of health, and long-term physical and psychological complications for military staff, civilians, and healthcare providers. Both pleasant and unpleasant changes in human life require a readjustment.

Objectives: The objective of this study was to explain the coping strategies of healthcare providers with tension resources during the Iran-Iraq war.

Methods: This was a qualitative content analysis conducted during years 2015 and 2016. The researcher collected, coded, and analyzed the data. In a survey conducted by the researcher, 119 written narratives of 101 healthcare providers during the Iran-Iraq war were collected. To analyze the data, the principles of conventional content analysis were used.

Results: The results of the analysis of 952 pages of written narratives in the relevant literature led to the emergence 8 themes. The main themes included acceptance, emotional release, denial and avoidance, shock and disbelieve, self-control, religious strategies, engaging in fun activities, and seeking social support.

Conclusions: Transforming the experiences and tacit knowledge of healthcare providers during the war to explicit knowledge could help to identify and analyze problems and provide appropriate solutions in similar scenarios. Also, it would be an effective solution for more effective coping and prevention of mental health problems. Similar studies are recommended to determine the coping strategies of healthcare providers using other methods of data collection including interviews with participants.
\end{abstract}

Keywords: Adjustment, Coping, Healthcare Providers, Iran, Iraq, Qualitative Research

\section{Background}

Every war imposes enormous harm to human resources. Workforce and its maintenance are very important in operational areas. Wars will lead to defeat if workforces are not properly protected (1). Healthcare providers, including nurses, physicians, and rescuers have key roles in handling critical conditions and provide the highest quality care. Caring, education, defense, leadership, and management are important roles of this group in conflict. Care during the war is a multidimensional concept affecting physical, emotional, and psychological aspects of care providers. The nature of care during the war is very unique and is different from stable situations (2).

The Iran-Iraq war that began in September 1980 and ended in August 1988 inflicted enormous human costs, as each side sustained hundreds of thousands of casualties (3). Medical staff tried to treat the wounded during the war and were themselves not secure from injuries, and more than 4000 doctors, nurses, paramedics, and rescue work- ers, were killed (4). Also, many studies indicated physical and psychological trauma in healthcare providers during the war (2, 5-9). In some studies, military healthcare providers reported exposure to pain, death, and dying, inadequate physical conditions, caring for extremely large numbers of wounded, heavy work load, disturbances in sleep pattern, long working hours, anxiety, exhaustion, limited facilities and time to save the wounded $(5,10)$, panic, stress, depression $(8,10,11)$, post-traumatic stress disorder (PTSD) $(5,8,10,11)$, and emotional tensions (2). Scannell-Desch and Doherty explained experiences of US military nurses in the Iraq-Afghanistan war. In their study, an emerged theme was "my wartime stress: I'm a different person now" and a sub-theme was "homecoming: a difficult adjustment". These concepts focused on PTSD and adjustment problems after returning home (10). Evidence showed that the quality of healthcare depends on many factors, including the health and work ability of healthcare workers. There is growing understanding that 
work-related stress negatively affects the health of workers (12). It is obvious that failure to resolve stress in the longterm could have serious professional and personal consequences $(5,13)$. Stress could be regarded as a psychological threat, in which the individual perceives a situation as a potential threat (13).

Any change, both pleasant and unpleasant, in human life, requires readjustment. Evidence shows that strategies for coping with life changes and tensions resulting from them are different in people (14). Lambert and Lambert reported workplace stressors of nurses and their coping strategies in their study (15). Some coping strategies that emerged from the literature included teamwork, leadership, and shared values (16). Researchers have found that socio-economic, ethnical (13), cultural (12,13), personal, and psychological factors (12) influence coping behaviors. Some researchers have found that coping strategies that are more problem-focused tend to occur more often in Western cultures and emotion-focused strategies have often been found in Asian cultures (15). Having an understanding of health caregivers' experiences could assist the healthcare system in the event of future crises. Very little has been written about their experience in the Iran-Iraq war. In a historical study, Iranian nurses reported that they had not been prepared for care during the war, nonetheless, they managed to quickly adapt themselves to the conditions of the war and to carry out their duties with success (3).

Investigating the experiences of healthcare providers in coping with stressors during wartime provides valuable insight for the contemporary health system. These experiences will be very useful in the formulation of a clinical information system.

The advantages of such systems include the development of a prevention program of mental disorders resulting from war, determination of baseline data in this field, and reduction of the effects of political, economic, cultural, social, emotional, and psychological diseases caused by war trauma. These systems could also prevent the progress of mental disorders and reduce social problems and their economic burden with special and immediate attention to mental health, access to accurate information, timely feedback, and recognition of people in need of psychological support.

Iranian researchers have documented many experiences of this group. However, most of these texts are narrative memories of healthcare providers and scientific analysis has not been performed on them, despite the fact that studying these documents and their scientific analysis could lead to fruitful results. For example, identification of coping strategies of healthcare providers in stressful conditions of war needs to be investigated further.
Increased insight and understanding of these strategies could strengthen these mechanisms to cope with the potential crises in the future. Thereby, the health and quality of life of healthcare providers will be improved and consequently, the quality of care will increase. Qualitative research is an approach that could help in this field.

\section{Objectives}

The objective of this study was to explain the coping strategies of healthcare providers under tension during the Iran-Iraq war.

\section{Methods}

\subsection{Design and Sample}

This was a qualitative study, which used conventional content analysis and was conducted during years 2014 and 2016. The target population was healthcare providers. The study population consisted of healthcare providers that took care of veterans, wounded, and martyrs in the IranIraq war.

\subsection{Data Collection and Analysis}

There are numerous texts about memories, diaries, and written narratives of physicians, nurses, and rescuers and to a large extent their experiences have been covered. The researcher collected and analyzed 119 printed and electronic texts about experiences and memories of 101 healthcare providers in the Iran-Iraq war. The principles of conventional content analysis were used to analyze the data. This type of design is usually appropriate when existing theory or research literature on a phenomenon is limited. The researcher avoided using preconceived themes, and instead of allowed the themes and sub-themes and their names to flow from the data. Data analysis started with reading all data repeatedly to achieve immersion and obtain a sense of the whole phenomenon. Then, data was read word by word to derive codes by first highlighting the exact words from the text that appear to capture key concepts. Next, the researcher approached the text by memoing and making notes of her first impressions, thoughts, and initial analysis. Emerging initial codes were sorted into themes and sub-themes based on similarities and differences. In this process, both manifest and latent content analysis was performed to achieve the final themes that could be extracted. Also, constant comparison analysis was used and extracted themes and sub-themes were compared and reviewed repeatedly with each other and with initial data. Concepts and meanings that were indicative of a subject were put together and themes and 
sub-themes emerged. Emerged tentative themes were reviewed by the researcher and peer and necessary revisions were made. The main focus of the analysis was to discover coping strategies of healthcare providers in the Iran-Iraq war. The process of collecting and analyzing the data continued until saturation.

\subsection{Rigor}

Prolonged engagement of the researcher with the phenomenon under study (over 24 months), precise recording and reporting of all stages of the research, limited review of the literature, peer reviewing, and full immersion in the data increased the trustworthiness of the study. It should be noted that the researcher had the experience of qualitative research. Also, the researcher interacted with combatants, who defended the country in the Iran-Iraq war and healthcare providers, who took care of the wounded.

\subsection{Ethical Considerations}

The present study was approved by the ethical committee of AJA University of Medical Sciences. The researcher committed herself to respecting the rights of the authors in the use of printed and electronic texts and laws relating to the publication of literature.

\section{Results}

\subsection{Acceptance}

The healthcare providers referred to accepting the martyrdom of a child, coping with limb amputation, accepting and coping with the catastrophes of the war.

\subsection{Emotions (Feelings)}

Informants showed various forms of emotions and feelings, such as crying, anger, and anxiety.

\subsubsection{Crying}

This sub-theme was repeated consistently. When healthcare staff encountered the stressful situations of war, they used this approach. This strategy was more commonly used when they faced young wounded patients or extensive injuries. A nurse explained her reaction to an extremely injured case:

"I see the injured soldier. I cried involuntarily, as he was so young." $\mathrm{P}_{1}$

\subsubsection{Anger and Nervousness}

The anger and nervousness strategy was rarely used by healthcare providers.

"When all the wounded were delivered (to a hospital in Tehran), I went looking for critically injured illness inside the hospital. Some staff was nagged, and with annoyance said "this time of night? He has severe injuries!" I told with anxiety, "Call the surgeon quickly unless war has day and night? This man is a war wounded." After moaning and do frown they said: "This hospital doesn't have the blood. I angrily told you make the operation room ready, I will give the blood myself." $\mathrm{P}_{1}$

\subsection{Deny and Avoidance}

"Deny and avoidance" were rarely used by informants. For instance, a nurse denied her husband's martyrdom. Some informants used an avoidance strategy because of the fear of knowing the reality of one the family member's martyrdom or injury. Moreover, avoidance of watching a martyr, avoidance of asking his name, and not looking at an injured mother's eyes were other instances that were mentioned by informants. An informant had written about the death of her brother:

"I said goodbye to them (her family) under the pretext of being on shift and came back to the Jurjani hospital." $P_{2}$

\subsection{Shock and Disbelief}

This coping strategy was used at the beginning of encountering tension. Seeing severe injuries, several martyrs and injured soldiers, family members or colleagues, and friends martyrdom, starting and ending of the war, the reaction of the martyrs' family, acceptance of the united nations security council (UNSC) resolution 598, death of Imam Khomeini, lack of facilities, and seeing hypocrites corps were emerged codes that explained shock and disbelief of informants. A physician mentioned the reaction of the Shahid Rajaie hospital staff on 20th of July 1987 to the UNSC resolution 598 acceptance:

"All were shocked." $\mathrm{P}_{2}$

One of the hospital supervisors pointed out to happiness and disbelief of the staff when they found out that their colleague, who they thought was martyred, was actually alive:

"I was shocked from that scenery." $\mathrm{P}_{20 \mathrm{~N} 2}$

\subsection{Self-Control}

This strategy includes patience and tolerance, feeling control, and keeping composure. 


\subsubsection{Patience and Tolerance}

Patience and tolerance against family member's injury or martyrdom, tolerance against problems of the hospitals, and patience and tolerance while being seized by the enemy were mentioned by informants. An informant mentioned that she did not have the strength to see her husband's serious injuries.

\subsubsection{Feeling Control}

Informants tried to cope with their feelings while being tensioned and they tried to avoid showing their nervousness to others. Feeling control and wisdom were of most importance amongst the staff in the critical conditions of patients care and treatment.

\subsubsection{Keeping Composure}

Of other useful strategies used by staffs while they were treating injuries was being cool. A physician mentioned her calmness against enemy attacks:

"I was surprised of my calmness." $\mathrm{P}_{2}$

On the other hand, a personal support worker mentioned the distraction of the staffs in the similar conditions.

"After the severe raid attack of the enemy in Shahid Beheshti hospital and the congestion of the martyrs and injuries, we were all distracted." $\mathrm{P}_{17 \mathrm{~N} 2}$

\subsection{Religious Approaches}

One of the coping strategies found numerous times was the religious approach, which included belief in God, praying, trust and recourse, giving thanks, doing religious duties, and accepting destiny.

\subsubsection{Belief in God}

Belief in God was one of the most important and applicable strategies used by informants. Belief in God led to better tolerance of overwhelming captivity conditions and treatment of injuries under stressful conditions of the hospitals. The writing told about trust and belief of the fighters and healthcare staffs. A physician talked of sending her son to the battle zone, which showed her belief and trust in God:

"Although I did not want my son to go far away, I smiled with difficulty and said: Go my darling, God will be always with you. Remember any action you want to do is just for God's sake." $P_{2}$

An informant that had the experience of several years of captivity in Iraqi prisons mentioned in his diary that the prisoners with strong beliefs in God became adapted to the situation more easily, and vice versa.

\subsubsection{Pray and Litany}

One of the coping strategies, which was seen several times in the data was praying and litany of the informants, which made them more adaptive. Praying for the injuries healing, praying during the injured martyrdom and praying to release from enemy's attack was abundantly seen. A nurse said:

"The voice of Sahifeh Sajaddieh litany gives me a good feeling. ... I passed the dawn with it being broadcasted on the radio. It was part of my essence each night." $\mathrm{P}_{1}$

Under critical conditions, the informants adapt themselves by praying and litany and they tried to cope with the stress:

"My mother prays and oaths to Prophet Danial. Murmuring of all people praying was like a tunable song and it decreased stress and fear of the terrible sound of the planes." $\mathrm{P}_{23}$

\subsubsection{Trust and Recourse}

Trust in God to save the injured persons, trust in God during the attacks of the enemy, refuge to holy places within the enemy attack, pilgrimage of the prophets during captivity and obtaining partial calmness as a result of trust in God emerged from data. A personal support worker that had refuged to the Prophet Denial holy shrine explained about her trust to God in order to be released from the enemy attacks:

"During the enemy attack, my mother said: Tooba, my darling, trust in God. We refuge to his prophet." $\mathrm{P}_{23}$

\subsubsection{Giving Thanks to God}

Giving thanks was due to overcoming problems and stress of the war, oneself or one's family staying healthy, healing injuries, creating a spiritual and psychological change within the staffs and caring and treatment of the wounded, freed from captivity was listed in the data abundantly. One physician told:

"This patient had remained in the same place thirtyfive to forty days until the next attack. ... Dr. Semnanian and I took the worms from his leg. Mercifully, Dr. Fazel performed a debridement on the leg we did not have any hope to keep, and it was unbelievably healthy." $\mathrm{P}_{86}$

\subsubsection{Religious Duties}

Informants pointed out that even under the most difficult circumstances and despite having lots of work, they did not leave their religious duties so they became calm and coped with the stressful condition of the war.

"Sometimes when a mission was finished, the number of wounded was so much that we prayed quickly to avoid losing time." $\mathrm{P}_{1}$ 
Sometimes religious duties were done by the captives away from the sight of Iraqi soldiers in prison.

\subsubsection{Fatalism}

Fatalism is a miraculous rescue out of death being under the will of God, which was abundantly seen in the data. Informants used their knowledge, skills, and experiences to treat and cure the wounded yet they believed that the final result was in God's hand. A physician pointed out to his life after an imminent death:

"Destiny was as follow, we remained alive after an accidental movement and this being alive was repeated several times." $\mathrm{P}_{76}$

Informants believed that working in the battle field and taking care of the wounded was due to God's will and they overcame the problems with this thought.

\subsection{Addressing Fun Activities}

Despite facing work overload most of the time yet sometimes they performed religious, cultural, sports, and fun activities. Holding a poetry night, memorizing, interpreting and reading the Quran, holding of congregation prayer, sports exercises, talking with each other, making items with recycled products were codes that were found in the data. These activities allowed the person to tolerate the stress from war and facilitated their adaptation. A nurse had written:

"I loved the cemetery of martyrs as it had the smell of Ahmad (her husband that was a martyr). After the cemetery of martyrs, we went to the mosque or Imam Zadeh Sabzeh-Ghaba, which was very calming." $P_{1}$

\subsection{Seeking Social Support}

\subsubsection{Support of the Family, Friends, and Colleagues}

Most of the people at the front were supported by their families and it strengthened their heart. They also mutually supported their family and colleagues. One nurse, whose husband was wounded and was by his side at all stages of treatment said:

"The nurse moved the wheelchair. Ahmad (nurse's husband) moved his head difficulty and said: Zahra look at other wounded. Their condition is worse than me. I am not hurt at all." $\mathrm{P}_{1}$

The support of family members and colleagues of each other during the entire war, captured prisoners, the presence of healthcare staff in the battle field, and returning back from the battle field was continued. One physician wrote about the spiritual and psychological supports of the colleagues:

"Suddenly a terrible sound woke me up. An ambulance braked heavily. The ambulance driver jumped out quickly and began to yell. All his body was shaking. Mr. Sharifi (one of the members of the Board of Trustees of the Masjid-oAlnabi) got up, and took the driver's hands and spoke with composure with him: my brother why are you scared? The final destination of this road is martyrdom and of course, it is not reachable for everyone. The driver became calm and got in the car." $\mathrm{P}_{2}$

\subsubsection{Discontent of Some Families Towards Dispatch of the Staff to the Front}

There were some people that reported some of their family members in the battle field were unhappy and worried. An informant, whose wife was martyr, regarding her decision to go to the front had written:

"Ahmad's mother (nurse's mother-in-law) was very upset. It was her opinion that the front was not suitable for ladies, especially for a sad girl like me." $\mathrm{P}_{1}$

\subsubsection{Public Supports}

Iranians supported warriors and healthcare providers during the entire war. Public support was not only a unique spiritual support, they used everything that could be of interest. Donations were very important in the management of hospitals and health resources to treat and take care of the wounded. It included physical help to carry the wounded and to prepare clothing, linen, and medications for the wounded. A physician recalled in his diary that in the Valfajre 8 Operation, in which Iran encountered the chemical attacks of the enemy, and the Jorjani hospital faced a serious lack of facilities:

"Not an hour after that a lot of people were in front of the hospital. Little by little the entrance hall of the hospital was filled with the new sheets and clothing and canned food. Those with a better financial situation took the medications and medical equipment list and after about two hours came back with oxygen tents, antibiotic ampules, silver sulfadiazine ointments etc." $\mathrm{P}_{2}$

\subsubsection{Gratitude}

The majority of Iranians showed their gratitude to the warriors and medical team during the war. When people returned from the battle field or at the return of prisoners to their homeland, they were welcomed with open arms. One of the expeditionary forces to war zones wrote in her memories:

"We were surprised by seeing lots of people welcoming us with candies and sweets." $\mathrm{P}_{1}$

Even after many years of the Iran-Iraq war, authorities and other people show gratitude towards the treatment team. Of course, a few people were there that did not know the afflictions of the warriors and the medical team in the 
battle field and they hurt them with their words and behavior. An informant wrote about this subject:

"A young man said: I don't know what's going on in the battle field that somebody would insist to go? Another man told him to be sure that there is something for earning, that we are not informed about. The salary for the mission would also double. Their indifferent mood and status suggested that talking with them is useless." $\mathrm{P}_{1}$

\subsubsection{International Supports of the Captives}

The delegates of the united nations and the international committee of the red cross were organizations that visited the prisoners in military jails of Iraq and after, a slight improvement in their situation was achieved. This was listed in the diary of some informants and it was said that UN visits reduced the difficult circumstances of their captivity.

\section{Discussion}

The results of this study indicated the adaptation of participants to the stressful situation of war. In this regard, Biedermann et al. reported that nurses that worked in Vietnam quickly adapted themselves despite the lack of clinical experience, inadequate preparation, fatigue and emotional trauma of their new environment (17). Also, Firouzkouhi et al. found that the majority of nurses and rescuers, who joined the armed forces in the Iran-Iraq war, could quickly adapt with the condition despite having no previous training, and performed their task very well (3).

"Acceptance and expression of emotions" was one of the strategies for adaptation of the participants that led to the reduction of stress and anxiety and better coping with the conditions. Obviously, being in a stressful situation leads to stimulation of emotions. The ability to adapt will be improved by expression of emotions and feelings. Seyedfatemi et al. studied experienced stressors and coping strategies among Iranian nursing students. They reported that $35 \%$ of students used crying strategies and $57.1 \%$ expressed anger (13). Hagerty et al. also reported that a few military nurses experienced fatigue, nervousness, and inability to show empathy, gentleness, and care (5). These findings were emphasized by the present study.

"Denial and avoidance" were rarely used by the participants. These strategies can be helpful in the short term, yet if a person has used it in the long time, it could lead to depression and incompatibility. Ribeiro et al. studied the coping strategies of nurses in hospital emergency care services. In their study, the mean score of distancing strategy and escape and avoidance were $1.02 \pm 0.91$ and $1.15 \pm 0.95$, respectively (18). The use of the avoidance coping strategy has also been reported in the study of Seyedfatemi et al., (13) that was in accordance with the present study.

The "self-control strategy" included patience and maintaining control of emotions and coolness. This strategy leads to better control of the position and increased power of the participants to cope with a stressful situation. Ribeiro et al. reported that nurses in the emergency ward used a self-control strategy (18). Psychological coping strategies, such as trying to change the thinking and control of emotions and reconstruction of experiences have also been reported by another study (5). Researchers have indicated that self-control strategies are frequently used in Australia, China, Japan, New Zealand, South Korea, Thailand, and the United States of America (15). The results of these studies are in agreement with the present study.

Religious strategies included faith in God, praying and chanting, trust and recourse, giving thanks, doing religious duties, and fatalism, which were frequently used by informants. This strategy was more often used in Asian countries and Islamic communities and it is an effective approach in adaptive coping. In one study, religion and faith were mentioned as coping strategies used by the nurses (16). Salaree et al. reported that Iranian nurses believed that the pressures and problems will be tolerated by trust in God and having a spiritual vision. They believed that religious beliefs provide health and security for the community. Religion and spiritual beliefs give meaning to nursing interventions and help nurses tolerate the situation better (12). Muslims believe that problems are a celestial test and they become calm remembering God. The researchers noted the role of spirituality in job satisfaction of nurses. They showed that nurses consider nursing as a religious duty and the principle is the consent of God and receiving spiritual rewards (12). Also, studies have shown that religious strategies are a source for emotional support, social support, and hope. Therefore, those, who used this strategy in their daily lives experienced less depression and anxiety than other people (19). In another study, researchers showed that religion creates positive feelings by increasing the ability to cope with stress, the creation of social support environment, creating hope, and optimism that lead to an increase in the health of people, and more satisfaction in life (20). In a study by Seyedfatemi et al. spiritual strategies, such as praying, were frequently used by participants (13). These studies were in agreement with the present research. In fact, people with religious beliefs showed better coping with stressful situations rather than non-religious persons, thus their negative feelings and anxiety were less and they enjoyed more social supports. Therefore, religion and religious beliefs have a close relationship with psychological health and are one of the most effective factors on adaptation. 
The findings showed that sometimes the medical staffs proceed towards other affairs, including cultural activities, sports, promotion of religious values, and fun in their off-duty time. Addressing these matters was one of the coping strategies in reducing stress effectively. Similar findings have been reported in other studies. For example, "diversions from war: a piece of the home" emerged in Scannell-Desch and Dorothy's study. They mentioned that the nurses in the Iraq-Afghanistan war were trying, in their off-duty time, to perform their favorite daily activities, such as line-dancing, game nights, discussion groups, sport, watching movies, listening to music, passing educational courses, and religious programs, exactly like they did at home (10). In another study, doing exercise for health and fitness and the chance to converse with colleagues were mentioned as one of the strategies used by nurses (16). In a study by Seyedfatemi et al. listening to music and the relaxation strategy were commonly used by the participants (13). Hagerty et al. also reported that the coping strategies used by military nurses were individual activities such as yoga, running, massage, and writing diaries (5). Evidence has indicated that these affairs help the psychological health of individuals and the results of this study are in accordance with these results.

Another strategy was enjoying and seeking social support. In this regard, Scannell-Desch emphasized the importance of the existence and maintaining supportive systems, the necessity of maintaining friendly relations with other colleagues and family members and trusting them in a war environment (21). In a study by Seyedfatemi et al., the strategy of seeking social support was applied by the nursing students that included gratitude towards people, trying to help others to solve problems and keeping friendships with others and finding new friends (13). Also, group support and team work, including coping strategies, were used by nurses in the study of Hagerty et al. (5). Researchers showed that seeking social support is abundantly used by nurses in Australia, Japan, New Zealand, and South Korea (15) and the findings of the present study were in agreement with these findings.

One limitation of this study was the lack of access to informants in order to confirm the memories raised in the texts, however with the large number of documentations reviewed, this limitation is somewhat moderated.

Overall, the results of this study showed that the conversion of tacit knowledge and experiences of healthcare staff, particularly doctors and nurses during the Iran-Iraq war to explicit knowledge could be used in identifying and analyzing problems and adopting appropriate strategies in similar scenarios. These experiences will be effective in the production of knowledge for healthcare providers in abnormal and critical situations. Also, psychological dis- orders could be prevented by special attention to the mental health of staff, access to true information, timely feedback, and recognition of people in need of psychologicalbehavioral support. Therefore, social and economic problems caused by mental illness and the heavy costs of diagnosis and treatment on the health system will be decreased. Therefore, the better quality of care for the wounded could be achieved.

Similar studies are suggested to determine the coping strategies and experiences of healthcare staff in a critical situation with the use of other methods, such as quantitative studies and interview with informants.

\section{Acknowledgments}

The author would like to thank all of the participants in this study.

\section{Footnotes}

Authors' Contribution: Zahra Farsi was involved in the planning, data collection, data analysis, and writing of the manuscript.

Financial Disclosure: The author declares that she had no competing interests.

Funding/Support: This research was funded by a grant from the AJA University of Medical Sciences.

\section{References}

1. Ghanjal A, Sadri Arhami A, Basam S. Rescue and transportation experiences of medical department of Sepah in Valfajr 4 operation [In Persian]. J Military Med. 2003;5(2):91-8.

2. Rahimaghaee F, Hatamopour K, Seylani K, Delfan V. Nurses' perceptions of care during wartime: a qualitative study. Int Nurs Rev. 2016;63(2):218-25. doi: 10.1111/inr.12240. [PubMed: 26849972].

3. Firouzkouhi M, Zargham-Boroujeni A, Nouraei M, Yousefi H, Holmes CA. The wartime experience of civilian nurses in Iran-Iraq war, 19801988: an historical research. Contemp Nurse. 2013;44(2):225-31. doi: 10.5172/conu.2013.44.2.225. [PubMed: 23869507].

4. Farsi Z, Azarmi S. A review of documented experiences of health care professionals during wars, with a focus on Iran-Iraq war. Mil Caring Sci. 2016;2(4):246-53. doi: 10.18869/acadpub.mcs.2.4.246.

5. Hagerty BM, Williams RA, Bingham M, Richard M. Military nurses and combat-wounded patients: a qualitative analysis of psychosocial care. Perspect Psychiatr Care. 2011;47(2):84-92. doi: 10.1111/j.17446163.2010.00275.x. [PubMed: 21426353].

6. Sirati Nir M, Ebadi A, Fallahi Khoshknab M, Tavallaie A. Experiences of wives of veterans suffering from combat-related post-traumatic stress disorder: A qualitative content analysis. Int J Commun Bais Nurs Midwifery. 2013;1(3):147-55.

7. Rivers FM, Wertenberger DH, Lindgren K. U.S. Army Professional Filler System nursing personnel: do they possess competency needed for deployment?. Mil Med. 2006;171(2):142-9. doi: 10.7205/MILMED.171.2.142. [PubMed: 16578985]. 
8. Ben-Ezra M, Palgi Y, Wolf JJ, Shrira A. Psychiatric symptoms and psychosocial functioning among hospital personnel during the Gaza War: a repeated cross-sectional study. Psychiatry Res. 2011;189(3):3925. doi: 10.1016/j.psychres.2011.02.004. [PubMed: 21354628].

9. Cuellar ET. Care and meaning in war zone nursing. Nurs Clin North Am. 2009;44(4):483-93. doi: 10.1016/j.cnur.2009.07.004. [PubMed: 19850184].

10. Scannell-Desch E, Doherty ME. Experiences of U.S. military nurses in the Iraq and Afghanistan wars, 2003-2009. J Nurs Scholarsh. 2010;42(1):3-12. doi: 10.111//j.1547-5069.2009.01329.x. [PubMed: 20487181].

11. Gibbons SW, Hickling EJ, Watts DD. Combat stressors and posttraumatic stress in deployed military healthcare professionals: an integrative review. J Adv Nurs. 2012;68(1):3-21. doi: 10.1111/j.13652648.2011.05708.x. [PubMed: 21635285].

12. Salaree MM, Zareiyan A, Ebadi A, Salaree M. Coping strategies used by Iranian nurses to deal with burnout: a qualitative research. Glob J Health Sci. 2014;6(6):273-80. doi: 10.5539/gjhs.v6n6p273. [PubMed: 25363109].

13. Seyedfatemi N, Tafreshi M, Hagani H. Experienced stressors and coping strategies among Iranian nursing students. BMC Nurs. 2007;6:11 doi: 10.1186/1472-6955-6-11. [PubMed: 17999772].

14. Delgado C. Sense of coherence, spirituality, stress and quality of life in chronic illness. J Nurs Scholarsh. 2007;39(3):229-34. doi: 10.1111/j.15475069.2007.00173.x. [PubMed: 17760795].
15. Lambert VA, Lambert CE. Nurses' workplace stressors and coping strategies. Indian J Palliat Care. 2008;14(1):38-44. doi: 10.4103/0973 1075.41934

16. Kenward LJ, Kenward G. Experiences of military nurses in Iraq and Afghanistan. Nurs Stand. 2015;29(32):34-9. doi: 10.7748/ns.29.32.34.e9248. [PubMed: 25850507].

17. Biedermann N, Usher K, Williams A, Hayes B. The wartime experience of Australian Army nurses in Vietnam, 1967-1971. J Adv Nurs. 2001;35(4):543-9. doi: 10.1046/j.1365-2648.2001.01870.x. [PubMed: 11529954].

18. Ribeiro RM, Pompeo DA, Pinto MH, Ribeiro R. Coping strategies of nurses in hospital emergency care services. Acta Paul Enferm. 2015;28(3):216-23. doi:10.1590/1982-0194201500037.

19. Garrosa E, Rainho C, Moreno-Jimenez B, Monteiro MJ. The relationship between job stressors, hardy personality, coping resources and burnout in a sample of nurses: a correlational study at two time points. Int J Nurs Stud. 2010;47(2):205-15. doi: 10.1016/j.ijnurstu.2009.05.014. [PubMed: 19596324].

20. Koenig HG, Larson DB, Larson SS. Religion and coping with serious medical illness. Ann Pharmacother. 2001;35(3):352-9. doi: 10.1345/aph.10215. [PubMed: 11261534].

21. Scannell-Desch EA. Lessons learned and advice from Vietnam war nurses: a qualitative study. J Adv Nurs. 2005;49(6):600-7. doi: 10.1111/j.1365-2648.2004.03335.x. [PubMed: 15737220]. 